\title{
Co-Digestion of Rice Straw Leachate and Domestic Waste Water for Biogas Production with Addition of Urea as Nitrogen Source
}

\author{
Syazwani Idrus, Sim Jian Zhe, Nurul Shafiqah Rosli, and Nik Norsyahariati Nik Daud
}

\begin{abstract}
This study investigates the methane production by anaerobic co-digestion of rice straw leachate (RSL) and domestic wastewater (WW). The experiment was conducted at a controlled mesophilic temperature of $38^{\circ} \mathrm{C}$ in Continuous Glass Reactor (CGR) for a period of approximately 12 weeks. The process performance was evaluated based on the efficiency of COD removal and methane production in relation to other parameters such as $\mathrm{pH}$, (organic loading rate) OLR and alkalinity. This study confirmed that the rate of COD removal for co-digestion of WW and RSL achieved the stable condition at $89.33 \%$, meanwhile the digestion of RSL with addition of urea was at $76.00 \%$. The addition of urea into RSL, showed the synergistic effect in anaerobic digestion as the removal rate of COD increased from $61.33 \%$ to $76.00 \%$. Meanwhile, methane production reached the highest value of $0.154 \mathrm{~L} / \mathrm{CH}_{4}$ at day 32 with the COD conversion ratio of $81.33 \%$. SEM analysis showed a change in surface structure of the granules and it was confirmed by EDX analysis that there was some light metal crystallisation and salt agglomeration on the sludge granule surface.
\end{abstract}

Index Terms-Anaerobic co-digestion, chemical oxygen demand, methane production, nitrogen and rice straw leachate.

\section{INTRODUCTION}

Rice is a vital source of food which can provide nutrients as well as calorie intake, and over half of the world's human population are depending on it as a main food source [1]. Rice straw as a by-product of rice production is one of the most abundant and renewable energy sources in the world. According to the data from Food and Agriculture Organization of the United Nations in year 2012, a total of 718 million tons of rice were produced which equates to approximately 969 million tons of rice straw available worldwide. According to the statistical data from the Department of Agriculture, Malaysia, the annual rice production of Malaysia in year 2010 is about 1.59 million tons with the generation of rice straw of approximately 0.88 million ton. The trend of global rice production is increasing in the last decade [2]. Hence, rice straw has becomes a relatively common agricultural waste and its biogas production potential has becomes a recent interest for numerous researchers. Rice straw is one of main agricultural

Manuscript received November 27, 2016; revised April 12, 2017.

Syazwani Idrus is with the Department of Civil Engineering, Faculty of Engineering, Universiti Putra Malaysia, Malaysia (e-mail: syazwani@upm.edu.my).

Sim Jian Zhe, Nurul Shafiqah Rosli, and Nik Norsyahariati Nik Daud are with the Department of Civil Engineering, Faculty of Engineering, Universiti Putra Malaysia, Malaysia. residues of second generation biomass that left in the field after harvest season. The availability of rice straw as the second biomass generation can be utilized as the valuable land resources for food production as well as producing energy from the waste. However, the improper disposal methods of rice straw such as natural decomposition in the field soil and open field burning are the actual scenarios that happen in recent years. In most of the Asian countries, the most common practice used in disposing the rice straw is by open-field burning or tilling the straw back into the field. In fact, both of these methods are contributing to the increase of greenhouse gas emissions [3]. The open burning of rice straw will release gases such as carbon dioxide, carbon monoxide, methane, non-methane hydrocarbons, nitrogen compounds, sulfur dioxide and particulate matters into the atmosphere. Among these greenhouses gases, nitrous oxide and methane are those which contribute significantly to global warming [4]. On the other hand, rice straw is also commonly tilled back into the soil and used as fertilizer for the crops. The decaying of rice straw in soil often releases gases such as nitrogen, hydrogen, methane, ammonia and hydrogen sulphide. Thus, it increases the methane emissions to the atmosphere and deteriorate the phenomena of global warming. Hence, there is a need to develop mitigations to remove field residues and capture methane to reduce the emission of greenhouse gases and use it as a source of energy. However, one of the main reasons for rice straw has not been selected as a substrate for energy production is, its complex and lignocellulosic structure which makes it difficult to be decomposed [5]. This is because the lignin component in rice straw which is resistant to anaerobic digestion acts as a shield and it can limit the hydrolysis process [6] Nevertheless, several factors such as the abundance of rice straw, discoveries of appropriate pre-treatment strategies and anaerobic co-digestion processes have proved that the value and potential of rice straw can no longer be overlooked as it can actually serve as a viable renewable energy that must be utilized to benefit the world populations. In the anaerobic digestion, microorganisms decompose the organic matters and produce biogas (mixture of methane and carbon dioxide) as a form of energy. Furthermore, the carbon to nitrogen $(\mathrm{C} / \mathrm{N})$ ratio is also play bigger role in anaerobic digestion. $\mathrm{C} / \mathrm{N}$ ratio of 20-30 reported as the optimal value which can promote biodegradation process. Straw has been identified as low in nitrogen content which is considered as essential nutrient for microbial growth. Hence, Anaerobic Digestion (AD) of very high $\mathrm{C} / \mathrm{N}$ ratio can be also limited by nitrogen availability [7], [8]. Therefore, urea has been proposed as source of nitrogen 
in order to overcome the deficiencies. Rice straw leachate (RSL) produced from the leaching of rice straw was studied in production of biogas and none of the previous study has been conducted focusing on the chemical oxygen demand (COD) removal, methane production between the co-digestion of RSL and wastewater (WW) as well as addition of urea as nitrogen source. Therefore, this study was conducted to examine the COD removal efficiency between the co-digestion process of RSL and WW in continuous glass reactor (CGR) and to investigate the effect of addition of urea as source of nitrogen on the COD removal in RSL digestion process.

\section{II.METHODS}

\section{A. Feed Substrate}

The mixture of two different substrates; RSL and WW were used for the co-digestion study. The domestic wastewater and activated sludge used were originated and collected from wastewater treatment plant at Faculty of Engineering, University Putra Malaysia. Meanwhile, rice straw samples were collected from a paddy field at Tanjung Karang, Selangor. It was preselected in order to remove particulate components which include tiny stones. Subsequently, the rice straw was dried and cut up into approximately uniform length before it was soaked in tap water. The RSL is produced in a ratio of $50 \mathrm{~g}$ of dried rice straw to 5 litres of tap water and left for soaking at least for three days.

\section{B. Reactor Design and Experimental Set-up}

Two reactors continuously glass reactor (CGR) shown in Fig. 1, were used for this study. The first CGR (Reactor 1) was filled with only RSL and additional of $1 \%$ to $3 \%(\mathrm{w} / \mathrm{v})$ of urea in aqueous solution. Urea added was used as the secondary source of nutrients and metabolic intermediate for the microorganisms during the anaerobic digestion process. The second CGR (Reactor 2) was filled with the mixture of RSL and WW. Total volume of the reactors is $1 \mathrm{~L}$ and total working volume of $900 \mathrm{~mL}$ with an effective volume activated sludge of $450 \mathrm{~mL}$. The top of the reactor was closed with rubber bung to trap the biogas produced inside the reactor. A hole was made at the centre of the rubber bung and a hollow stainless steel tube with approximate length of $3 \mathrm{~cm}$ to $4 \mathrm{~cm}$ was inserted into the hole. The stainless steel tube was then connected to a flexible tube with approximate length of $4 \mathrm{~cm}$ which used to direct the methane produced to a gas collection bag. The experimental work in this study was carried out in a laboratory-scale incubator. All CGRs were placed in the water bath (Memmert water bath, [STT1010-S2970], Vitar-Segatec Sdn. Bhd.) with controlled temperature of $38^{\circ} \mathrm{C}$ to serve as the working temperature for the anaerobic digestion process. This study was carried out for a total period of 12 weeks. The first two weeks were the adaptation period for the microorganisms in order to allow them to acclimatize to the experimental conditions as required. On the other hand, the remaining ten weeks, the experiment proceed with the anaerobic digestion of RSL with the addition of urea and the co-digestion of WW and RSL for production of biogas. The hydraulic retention time (HRT) was maintained at 24 hours.

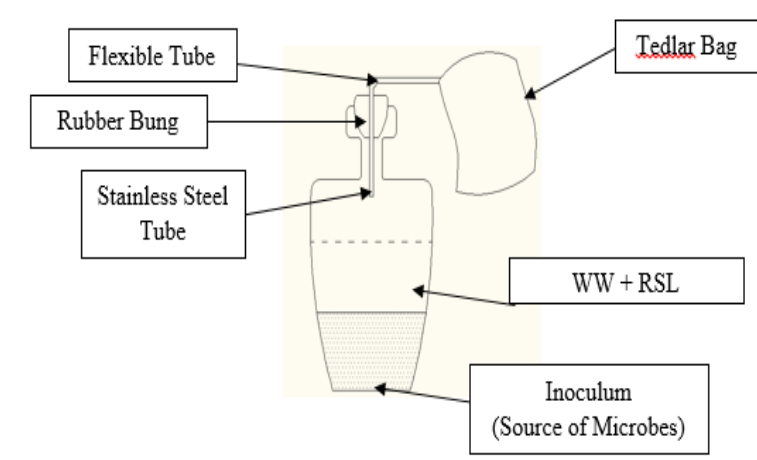

Fig. 1. Schematic diagram for the set-up of CGR.

\section{Analytical Methods}

The volume of biogas produced was collected using impermeable Tedlar bag (SKC Ltd, Blandford Forum) with an approximate capacity of 1.6 litres. The biogas collected was sampled by inserting gas syringe into the sampler and the composition of biogas was analyzed by using gas chromatography (GC). $\mathrm{pH}$ was measured by using $\mathrm{pH}$ meter (Delta 320, Mettler Toledo Group). COD was measured using a closed tube digestion and titration. Total solid and Volatile solid was measured using standard method 1684, U.S. Environmental Protection Agency (USEPA). Alkalinity was measured using standard method 8221, USEPA, Buret Titration Method.

\section{RESULTS AND DISCUSSION}

Characterization of rice straw leachate and wastewater.

The characteristics of the rice straw leachate were as follows (mg/L ): COD 800; TOC 350; TSS 78; K 120; Na 6; $\mathrm{Mg} 55$; Ca 74. The conductivity of the leachate was $432 \mu \mathrm{S} /$ $\mathrm{cm}$. The wastewater characteristics were $(\mathrm{mg} / \mathrm{L})$ : COD 800; TOC 350; K 25; Na 19; Mg 11; Ca 36; with conductivity $197 \mu \mathrm{S} / \mathrm{cm}$.

\section{A. Organic Loading Rate (OLR)}

Fig. 2 shows the OLR value for Reactor 1 and 2. The OLR for both Reactor 1 and 2 from Phase $A$ to $C$ is changing from $1.78 \mathrm{~g} / \mathrm{L} / \mathrm{d}$ to $0.89 \mathrm{~g} / \mathrm{L} / \mathrm{d}$. The adjusting of OLR is to determine the suitable and appropriate organic loading to be fed in the reactors. It was found the final OLR to be used for the regular feeding in both Reactor 1 and 2 is $1.33 \mathrm{~g} / \mathrm{L} / \mathrm{d}$ with the working volume of $450 \mathrm{ml}$ corresponding to the feedstock concentration of $0.60 \mathrm{~g} \mathrm{COD} / \mathrm{L}$. OLR of $1.33 \mathrm{~g} / \mathrm{L} / \mathrm{d}$ was chosen as the optimum working value instead of $1.78 \mathrm{~g} / \mathrm{L} / \mathrm{d}$, as at a higher OLR the reduction in $\mathrm{pH}$ value and fluctuation in COD removal rate was monitored, thus indicating the higher OLR might not be suitable for the anaerobic digestion process later. The OLR of $1.33 \mathrm{~g} / \mathrm{L} / \mathrm{d}$ is used for both Reactor 1 and 2 starting from Phase D until the end of the experiment

\section{B. $p H$ Value}

Fig. 3 shows the distributions of $\mathrm{pH}$ value for both Reactor 1 and 2 . In general, for all phases during the experiment, the $\mathrm{pH}$ values were maintained within $\mathrm{pH} 6$ to 7 . The first four phases (A to D), is known as the adaptation period where the CGR were only filled with WW for anaerobic digestion process. In Phase B, the $\mathrm{pH}$ value in both CGR is decreased 
gradually from pH 6.40 to a lowest value of pH 5.97 on Day 3. The reduction in $\mathrm{pH}$ value may be due to the high OLR value of $1.78 \mathrm{~g} / \mathrm{L} / \mathrm{d}$. The high OLR would eventually lead to the acid accumulation in the reactors which then causes the reduction of $\mathrm{pH}$ value. However, as the OLR reduced to $0.89 \mathrm{~g} / \mathrm{L} / \mathrm{d}$, the $\mathrm{pH}$ value increased gradually and returned to the range of above $\mathrm{pH} 6$ at Phase C. Over the next three cycles (Phase E to $\mathrm{G})$, the trend of $\mathrm{pH}$ values for both Reactor 1 and 2 were observed to be fluctuating between $\mathrm{pH} 6$ to 7 even though the OLR is kept constant at $1.33 \mathrm{~g} / \mathrm{L} / \mathrm{d}$. Although the ideal $\mathrm{pH}$ range for rice straw digestion was determined to be $\mathrm{pH} 7.5$ to 8.0, however, several batches of other experiments with rice straw have been successfully done in $\mathrm{pH}$ ranges of 6.5 to 7.3 [9]. Hence, this indicates that the anaerobic digestion process in both reactors were still stable.
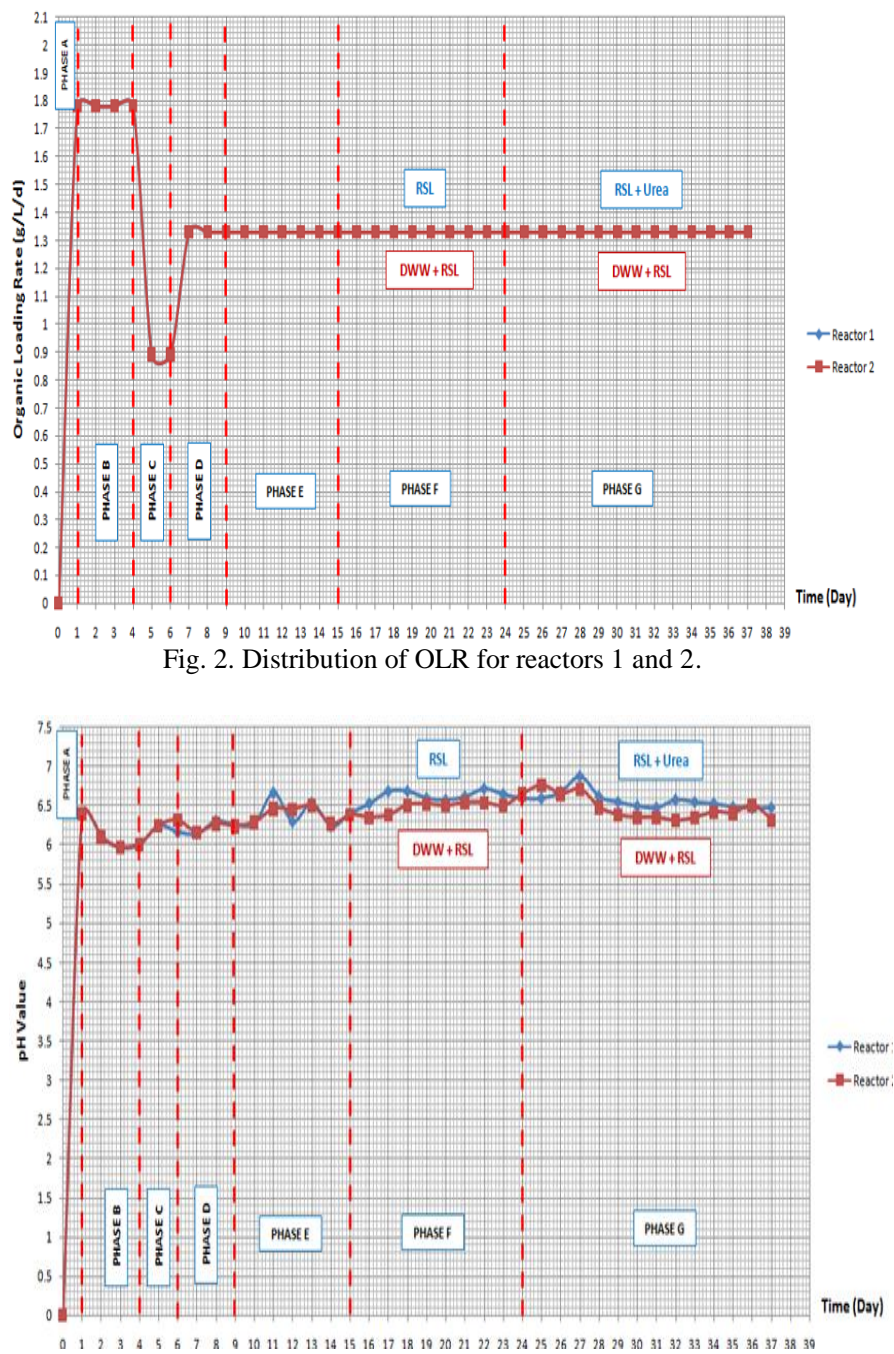
Fig. 3. Distribution of $\mathrm{pH}$ value for Reactors 1 and 2.

\section{COD Removal}

Fig. 4 shows the percentage of COD removal in Reactor 1 and 2. In Reactor 1, the COD removal for Phase A and B were observed to be fluctuated and the values achieved were less than $75 \%$. It could be explained as the microorganisms in the sludge are still adapting to the incoming organic loads. In Phase $\mathrm{C}$, the COD removal increased significantly up to $78.50 \%$ as the concentration of feedstock is decreased from $0.8 \mathrm{~g} \mathrm{COD} / \mathrm{L}$ to $0.4 \mathrm{~g} \mathrm{COD} / \mathrm{L}$. In other words, the reduction of OLR from $1.78 \mathrm{~g} / \mathrm{L} / \mathrm{d}$ to $0.89 \mathrm{~g} / \mathrm{L} / \mathrm{d}$ increases the removal of
COD. Hence, this shows that the lower OLR of feedstock can actually promote the ability of microorganisms in sludge to degrade or digest the organic materials, which then results in higher percentage of COD removal. The COD removal in Phase D increased gradually at OLR of $1.33 \mathrm{~g} / \mathrm{L} / \mathrm{d}$ and decreased significantly at the beginning of Phase E. This is because there is a change in the feeding materials from WW to the mixture of WW and RSL. The addition of rice straw which is a lignocellulosic biomass that consists of high lignin content can create difficulties for the degradation and digestion process in the reactor. Hence, the COD removal reduced from $85.67 \%$ to $73.33 \%$. However, the COD removal increased and fluctuated at above $80 \%$ for the rest of the days in Phase E. In Phase F, the COD removal in Reactor 1 decreased gradually from $84.00 \%$ to $61.33 \%$ with a difference of around $22.67 \%$. This significant reduction was due to the changes of the feeding material in the reactor from the co-digestion of WW and RSL to only RSL as a feeding material for the sludge. Once again, this shows that the RSL with high lignin content can actually inhibit the efficiency of COD removal in the reactor [5]. Besides, the lack of nitrogen in RSL which can limit the methanogenesis process also causes the reduction in COD removal efficiency. Hence, in Phase $\mathrm{G}$ in order to enhance the COD removal, urea was added as shown in Table 1. The addition of urea is aimed to provide the source of nitrogen as the macronutrient in order to enhance the anaerobic digestion process [10]. As a result, the COD removal in Reactor 1 increased gradually upon the addition of urea and achieved the stable state of COD removal of $76.00 \%$ with a difference of $14.67 \%$ to the lowest value in Day 24. This also indicates the synergistic effect in the COD removal of Reactor 1 due to the addition of urea. This finding indicates the role of arbon to nitrogen $(\mathrm{C} / \mathrm{N})$ ratio in anaerobic digestion where nitrogen in urea can enhance biodegradation process [7][8]. In Reactor 2, the condition and trend of COD removal from Phase A to $\mathrm{E}$ are relatively similar with those in Reactor 1 . The difference of Reactor 2 is that this reactor is set to be served as the control sample for this experiment. Hence, the feeding material in Reactor 2 is remained unchanged at OLR of $1.33 \mathrm{~g} / \mathrm{L} / \mathrm{d}$ from Phase $\mathrm{E}$ to $\mathrm{G}$ which is the co-digestion of WW and RSL. This is to compare the efficiency of co-digestion of WW and RSL and the digestion with only RSL. The results show that the COD removal for the co-digestion in Reactor 2 is increased and fluctuated from Day 17 to the end of the experiment. The highest COD removal being recorded was on Day 31 and 32 with value of $92.00 \%$ and the reactor achieved the stable state with the COD removal of $89.33 \%$. In stable state condition, the difference of COD removal rate for Reactor 1 and 2 is approximately $13.33 \%$. In short, the co-digestion process in Reactor 2 performs better than in Reactor 1 in term of COD removal because co-digestion process can provide not only the necessary microorganisms but also the appropriate balance of nutrients to create favourable conditions for the methanogens to thrive as shown in Table 2 and Table 3 [4].

\section{Biogas Production}

Table IV shows the percentage of biogas production with the addition of urea in Phase $G$ for Reactor 1 . The biogas produced from the anaerobic digestion are methane and 
carbon dioxide with their percentage respectively. The percentage of methane obtained deviates from $64.38 \%$ to $74.38 \%$ for Day 29 to 36 . On the other hand, the methane percentage recorded as $74.38 \%$ on Day 32 as the highest value. In relation to that, the COD removal rate for Reactor 1 in that particular day also achieved the highest value of $81.33 \%$. In correspondence to the COD removal rate of $81.33 \%$, the volume of methane produced is $0.154 \mathrm{~L} / \mathrm{CH}_{4}$. Based on the COD added to the reactor is $0.540 \mathrm{~g}$, the efficiency of COD conversion into methane is $81.33 \%$ as the theoretical value for methane production at OLR of 1.33 $\mathrm{g} / \mathrm{L} / \mathrm{d}$ is $0.189 \mathrm{~L} / \mathrm{CH}_{4}$. For the remaining days, the rates of COD removal were achieved at around $76 \%$ with an average volume of methane of $0.144 \mathrm{~L} / \mathrm{CH}_{4}$.

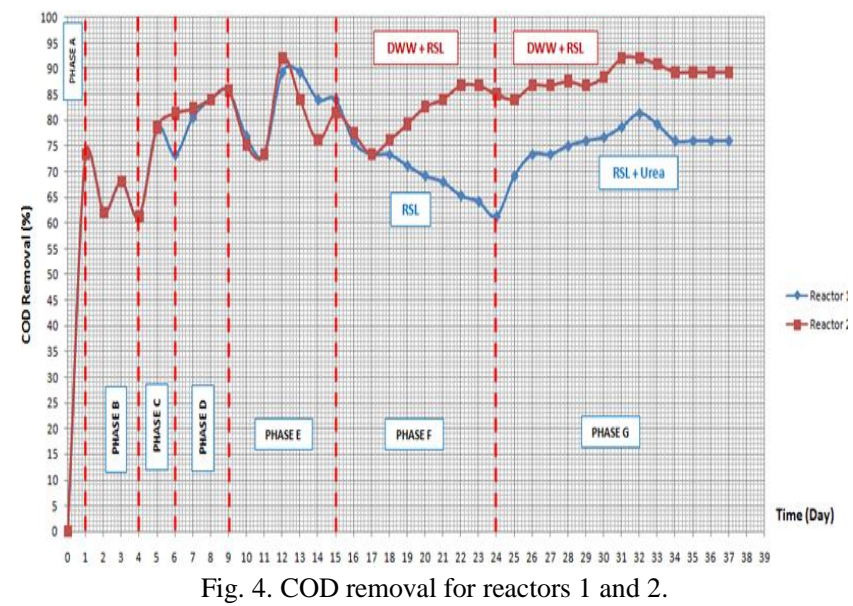

TABLE I: THE ARRANGEMENT OF CHANNELS COMPARISON OF METHANE PRODUCTION IN REACTOR 1 FOR FIVE DAYS

\begin{tabular}{|c|c|c|c|c|c|c|c|c|}
\hline Reactor & $\begin{array}{l}\text { Time } \\
\text { (Day) }\end{array}$ & Feedstock & $\begin{array}{c}\text { COD } \\
\text { initial }(g)\end{array}$ & $\begin{array}{l}\mathrm{COD}_{\text {final }} \\
(\mathrm{g})^{* \mathrm{~b}}\end{array}$ & $\begin{array}{l}\text { Theoretical } \mathrm{CH}_{4} \\
\left(\mathrm{~L} / \mathrm{CH}_{4}\right)^{{ }_{\mathrm{c}}}\end{array}$ & $\begin{array}{c}\mathrm{CH}_{4} \\
\text { produced } \\
\left(\mathrm{L} / \mathrm{H}_{4}\right)^{{ }^{*} \mathrm{c}}\end{array}$ & $\%$ of $\mathrm{CH}_{4}$ & $\begin{array}{l}\text { Deviation of } \mathrm{CH}_{4} \\
\left(\mathrm{~L} / \mathrm{H}_{4}\right)^{{ }^{* d}}\end{array}$ \\
\hline R1 & 29 & RSL $+2 \%$ urea & 0.540 & 0.410 & 0.189 & 0.144 & 64.33 & 0.045 \\
\hline $\mathrm{R} 1$ & 30 & $\mathrm{RSL}+2 \%$ urea & 0.540 & 0.414 & 0.189 & 0.145 & 66.26 & 0.044 \\
\hline $\mathrm{R} 1$ & 32 & $\mathrm{RSL}+3 \%$ urea & 0.540 & 0.439 & 0.189 & 0.154 & 74.40 & 0.035 \\
\hline $\mathrm{R} 1$ & 34 & RSL $+3 \%$ urea & 0.540 & 0.410 & 0.189 & 0.144 & 69.33 & 0.045 \\
\hline $\mathrm{R} 1$ & 36 & $\mathrm{RSL}+3 \%$ urea & 0.540 & 0.410 & 0.189 & 0.144 & 70.23 & 0.045 \\
\hline
\end{tabular}

*b results from COD removal in Reactor 1

$* \mathrm{c}$ calculated by assuming $1 \mathrm{~g} \mathrm{COD}=0.35{\mathrm{~L} / \mathrm{CH}_{4}}$

$* \mathrm{~d}$ calculated from the difference between theoretical yield and actual yield per gram of COD removed

TABLE II: COD BALANCE IN REACTOR 1

\begin{tabular}{|c|c|c|c|c|c|}
\hline \multirow{2}{*}{$\operatorname{OLR}(\mathrm{g} / \mathrm{L} / \mathrm{d})$} & \multicolumn{2}{|c|}{ Average Time (day) } & \multirow{2}{*}{$\begin{array}{c}\text { Initial } \\
\text { COD } \\
(\mathrm{g} \text { COD/L })\end{array}$} & \multirow{2}{*}{$\begin{array}{c}\text { Average COD } \\
\text { Removal }(\mathrm{g} \mathrm{COD} / \mathrm{L})\end{array}$} & \multirow{2}{*}{$\begin{array}{c}\text { Average COD } \\
\text { Removal Rate }(\%)\end{array}$} \\
\hline & From & To & & & \\
\hline $1.78^{* \mathrm{a}}$ & 1 & 4 & 0.80 & 0.529 & 66.13 \\
\hline $0.89^{*_{a}}$ & 5 & 6 & 0.40 & 0.304 & 75.88 \\
\hline $1.33^{*_{\mathrm{a}}}$ & 7 & 9 & 0.60 & 0.500 & 83.33 \\
\hline $1.33^{* b}$ & 10 & 15 & 0.60 & 0.497 & 82.83 \\
\hline $1.33^{* \mathrm{c}}$ & 16 & 24 & 0.60 & 0.414 & 69.00 \\
\hline $1.33^{* d}$ & 25 & 37 & 0.60 & 0.455 & 75.83 \\
\hline
\end{tabular}

*a acclimatization period with only WW digestion in Reactor 1

*b co-digestion period between WW + RSL in Reactor 1

*c digestion period with only RSL in Reactor 1

$*$ d digestion period of RSL + urea in Reactor 1

TABLE III: COD BALANCE IN REACTOR 2

\begin{tabular}{|c|c|c|c|c|c|}
\hline \multirow[b]{2}{*}{$\operatorname{OLR}(\mathrm{g} / \mathrm{L} / \mathrm{d})$} & \multicolumn{2}{|c|}{ Average Time (day) } & \multirow{2}{*}{$\begin{array}{c}\text { Initial } \\
\text { COD } \\
\text { (g COD/L) }\end{array}$} & \multirow{2}{*}{$\begin{array}{l}\text { Average COD Removal } \\
(\mathrm{g} \mathrm{COD} / \mathrm{L})\end{array}$} & \multirow{2}{*}{$\begin{array}{c}\text { Average COD Removal } \\
\text { Rate }(\%)\end{array}$} \\
\hline & From & To & & & \\
\hline $1.78^{* \mathrm{e}}$ & 1 & 4 & 0.80 & 0.529 & 66.13 \\
\hline $0.89^{* \mathrm{e}}$ & 5 & 6 & 0.40 & 0.304 & 75.88 \\
\hline $1.33^{* \mathrm{e}}$ & 7 & 9 & 0.60 & 0.504 & 84.00 \\
\hline $1.33^{* \mathrm{f}}$ & 10 & 37 & 0.60 & 0.505 & 84.17 \\
\hline
\end{tabular}

*e acclimatization period with only WW digestion in Reactor 2

${ }^{*}$ co-digestion period between WW + RSL in Reactor

\section{E. Surface Morphological and Mineral Contents of Sludge}

Fig. 5 shows the linkage of extra cellular polymeric substance on surface morphology of sludge feeding on domestic wastewater). Reference [11] has reported that exposure of granules to metals can lead to crystal development on the surface. This is as a result of the availability of a crystal-free surface due to poor overgrowth; this process of crystal formation is known as ripening [11]. Both these studies and the current research suggest that metals accumulation is in a crystalline rather than an amorphous form. After the anaerobic digestion takes place with rice straw washed water as the feedstock, the surface morphological changes to crystalline structure as shown in Fig. 6 and Fig. 7.

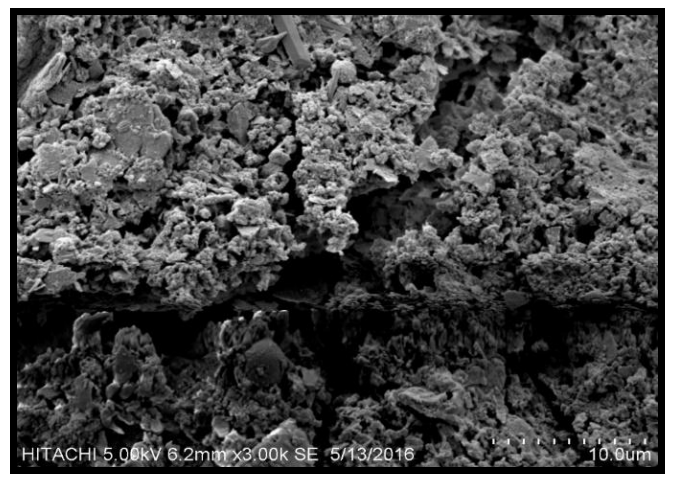

Fig. 5. Surface morphology of sludge feeding on domestic wastewater 


\section{F. EDX Analysis}

Fig. 8 showed the mineral content on the surface of the granule prior and after exposure to RSL.

Metals which includes Potassium (K), Silica (Si) and Sulphur (S) were found to increase $50 \%$ after feeding on RSL as compared to feeding on DWW (Fig. 9) which again indicate the accumulation of K, Si and S in RSL are possible. EDX result associated with crystalline structure as shown on surface morphology of granule.

\begin{tabular}{|c|c|c|c|c|c|c|c|c|}
\hline \multirow[b]{2}{*}{$\begin{array}{l}\text { Time } \\
\text { (Day) }\end{array}$} & \multirow[b]{2}{*}{ Reactor } & \multicolumn{4}{|c|}{ Biogas Percentage (\%) } & \multirow[b]{2}{*}{ Nitrogen $(\%)$} & \multirow[b]{2}{*}{ Oxygen (\%) } & \multirow[b]{2}{*}{$\begin{array}{c}\text { Other } \\
\text { Gases }(\%)\end{array}$} \\
\hline & & Methane & Methane $*^{\mathrm{a}}$ & $\begin{array}{l}\text { Carbon } \\
\text { Dioxide }\end{array}$ & $\begin{array}{c}\text { Carbon } \\
\text { Dioxide }^{* a}\end{array}$ & & & \\
\hline 29 & $\mathrm{R} 1$ & 4.12 & 64.38 & 2.28 & 35.62 & 76.02 & 17.53 & 0.05 \\
\hline 30 & $\mathrm{R} 1$ & 4.47 & 66.22 & 2.28 & 33.78 & 77.01 & 16.20 & 0.04 \\
\hline 32 & $\mathrm{R} 1$ & 6.01 & 74.38 & 2.07 & 25.62 & 76.53 & 15.34 & 0.05 \\
\hline 34 & $\mathrm{R} 1$ & 5.15 & 69.31 & 2.28 & 30.69 & 76.13 & 16.41 & 0.03 \\
\hline 36 & $\mathrm{R} 1$ & 5.05 & 70.23 & 2.14 & 29.77 & 76.34 & 16.43 & 0.04 \\
\hline
\end{tabular}

* ${ }^{\mathrm{a}}$ Percentage of biogas by considering only methane and carbon dioxide

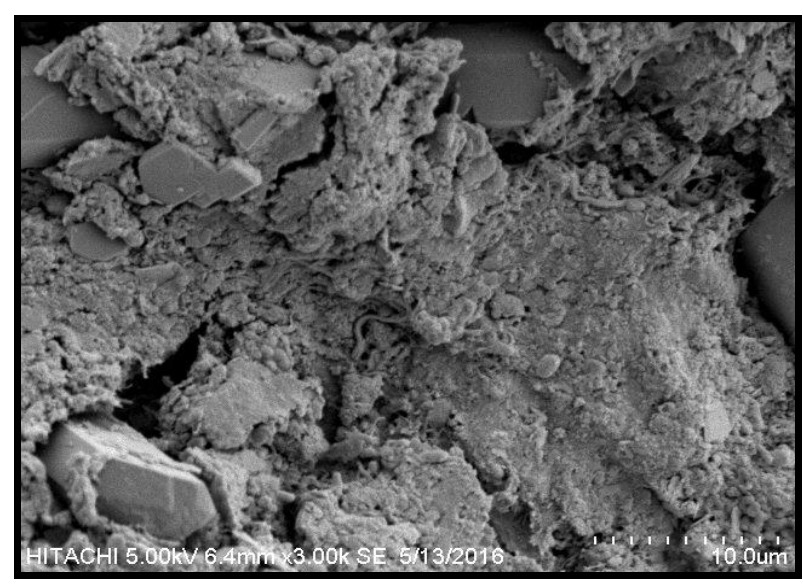

Fig. 6. Surface morphology for RSL feedstock.

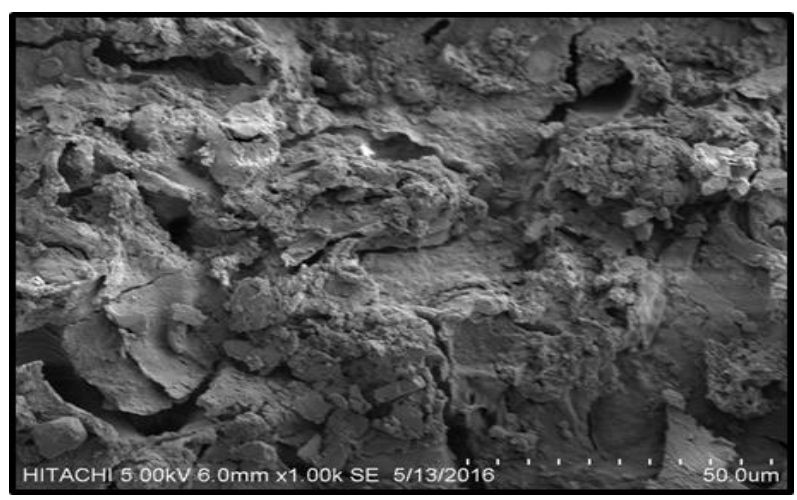

Fig. 7. Surface morphology for RSL with addition of urea.

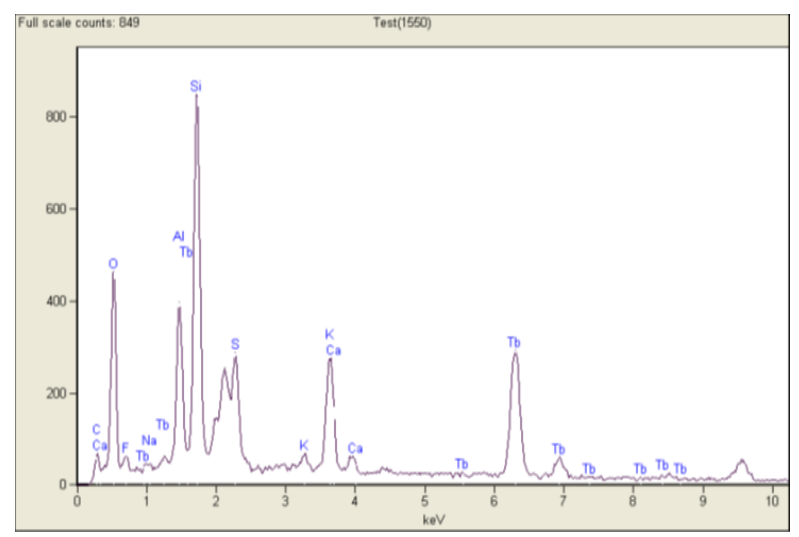

Fig. 8. EDX spectra for granule surface feeding on RSL

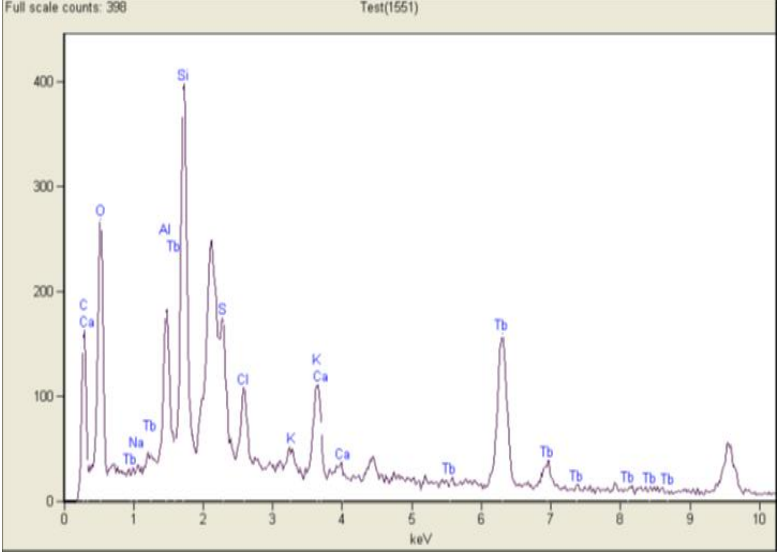

Fig. 9. EDX spectra for granule surface feeding on DWW

\section{CONCLUSIONS AND RECOMMENDATIONS}

The study confirmed that the rate of COD removal for co-digestion of RSL and WW achieved the stable state at Day 34 with $89.33 \%$. Meanwhile, the digestion with only RSL achieved the stable state at Day 34 with $76.00 \%$. This indicates that the co-digestion process performs better than the single digestion process as the rate of COD removal is higher. From the produced RSL, it is determined that the COD capacity for one tonne of dried rice straw mixed in 100,000 litres of tap water is, $17200 \mathrm{~g} \mathrm{COD/L}$. Hence, based on the experimental result, one tonne of rice straw could yield approximately $4148 \mathrm{~L}_{\text {of }} \mathrm{CH}_{4}$. Moreover, the addition of urea the final cycle enhanced the COD removal efficiency from $61.33 \%$ to $76.00 \%$. This indicates the synergistic effect of the addition of urea in RSL digestion process. The study shows that the highest rate of COD removal of $81.33 \%$ achieved in the digestion of RSL in Reactor 1 has the highest volume of methane production of $0.154 \mathrm{~L} / \mathrm{CH} 4$ at Day 32. This also indicates the highest efficiency of conversion of COD into methane of $81.33 \%$ with the theoretical methane yield of $0.189 \mathrm{~L} / \mathrm{CH} 4$. SEM analysis showed a change in surface structure of the granules and it was confirmed by EDX analysis that there was some light metal crystallisation and salt agglomeration on the sludge granule surface.

\section{ACKNOWLEDGEMENT}

The authors gratefully acknowledge the contributions of 
Universiti Putra Malaysia for financial support through Fundamental Research Grant Scheme (FRGS) 5524615.

\section{REFERENCES}

[1] I. S. Arvanitoyannis and P. Tserkezou, Corn and Rice Waste: A Comparative and Critical Presentation of Methods and Current and Potential Uses of treated Waste. Int Jour Food Sci and Technology, 43:958, 2008.

[2] Faostat. (2011). Global rice production by year. Food and Agriculture Organization of the United Nations. [Online]. Available: http://faostat.fao.org

[3] T. Abbasi and S. A. Abbasi, "Production of clean energy by anaerobic digestion of phytomass-New prospects for a global warming amelioration technology," Renewable and Sustainable Energy Reviews, 2010.

[4] B. Gadde, S. Bonnet, C. Menke, and S. Garivait, "Air pollutant emissions from rice straw open field burning in India," Environment Pollution, 2009.

[5] K. L. Kadam, L. H. Forrest, and W. A. Jacobson, "Rice straw as a lignoce llulosic resource:collection, processing, transportation, and environmental aspects," Biomass and Bioenergy; vol. 18, p. 369, 2000.

[6] T. V. Fernandes, G. J. Bos, G. Zeeman, J. P. Sanders, J. B. V. Lier, "Effects of thermochemical pre-treatment on anaerobic biodegradability and hydrolysis of lignocellulosic biomass," Bioresour Technol, 2009.

[7] R. Chandra, H. Takeuchi, and T. Hasegawa, "Methane production from lignocellulosic agricultural crop waste," A Review in Context to Second Generation of Biofuel Production Renewable and Sustainable Energy Reviews, vol. 16, no. 3, April 2012, pp. 1462-1476.

[8] U. Zaher, D. Cheong, B. Wu, and S. Chen, Producing Energy and Fertilizer from Organic Municipal Solid Waste Department of Biological Systems Engineering Washington State University Ecology Publication No. 07-07-024, 2007.

[9] B. E. Rittmann and P. L. McCarty, Environmental Biotechnology: Principle and Applications, vol. 36, pp. 145-149, 2001.

[10] P. C. Suryawanshi, A. B. Chaudri, S. Bhardwaj, and T. Y. Yeole, "Operating procedures for efficient anaerobic digester operation,"
Research Journal of Animal, Veterinary and Fishery Science, vol. 1, no. 2, pp. 12-15, 2013.

[11] H. Fang, H. Chui, and Y. Li, (1995). Microstructural analysis of UASB granules treating brewery wastewater. Water Science and Technology, vol. 31, pp. 129-135, 1995.

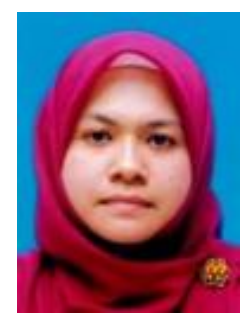

Syazwani Idrus obtained the $\mathrm{PhD}$ in biochemical engineering in year 2013 from Southampton University, England, United Kingdom. She was awarded a master degree in civil engineering major in environmental engineering in year 2007. In year 2005, she was awarded a bachelor degree in civil engineering. Both master and bachelor degree were awarded from Universiti Teknologi Mara, Malaysia. Her research interest is in the area of biochemical engineering - anaerobic conversion of biomass for biogas production, bio rector design - upflow anaerobic sludge blanket, continuous stirred tank reactor and anaerobic filter, synergistic and toxicity effect of metals on biodegradation rate during treatment of waste. Her current position is senior lecturer at Department of Civil Engineering, Faculty of Engineering, Unversiti Putra Malaysia (UPM) since 2013. In addition, she has been appointed to 2 administration positions which includes Head, Public Health Laboratory and Students' Affairs and Alumni Coordinator Civil Engineering Department.

She was appointed as a tutor since 2008 at UPM. 2 years before that, she worked as a civil engineer at Department of Environmental and Energy, Ministry of Works, Malaysia. She is a member of Board of Engineers Malaysia and member of International Water Association.

Currently she is the project leader and member for 6 research grants with total amount Ringgit Malaysia of 500,000.00. She has published more than 7 journals and presented at many international conferences which includes symposium on anaerobic digestion in Vienna, Austria and conference on future energy in Dubai UAE. She is supervising $3 \mathrm{PhD}$ students and 3 master degree students. 